\title{
Production and genetic characterization of interspecific hybrids among Crambe abyssinica, Crambe hispanica and Crambe kralikii
}

\author{
X.Z. Du ${ }^{1,2}$, B.L. Huang ${ }^{1}$, H. Guan' ${ }^{2}$ Z.Y. Li ${ }^{2}$ and B.Q. Huang ${ }^{1}$ \\ ${ }^{1}$ College of Life Science, Hubei University, Wuhan, China \\ ${ }^{2}$ National Key Laboratory of Crop Genetic Improvement, \\ Huazhong Agricultural University, Wuhan, China \\ Corresponding authors: Z.Y. Li / B.Q. Huang \\ E-mail: lizaiyun@mail.hzau.edu.cn / huangbangquan@163.com
}

Genet. Mol. Res. 13 (3): 6995-7005 (2014)

Received April 26, 2013

Accepted September 5, 2013

Published March 26, 2014

DOI http://dx.doi.org/10.4238/2014.March.26.2

\begin{abstract}
In this paper, interspecific crosses among Crambe abyssinica, Crambe hispanica, and Crambe kralikii were reported. In the $C$. hispanica $\mathrm{x} C$. abyssinica $(\mathrm{H} \times \mathrm{A})$ cross, $118 \mathrm{~F}_{1}$ hybrids were produced without embryo rescue, while $5 \mathrm{~F}_{1}$ hybrids were obtained with embryo rescue, when $C$. hispanica was used as the female parent. In the reciprocal cross (A x H), 232 hybrids were obtained without embryo rescue. From more than $1000 \mathrm{C}$. kralikii flowers pollinated with pollen grains of $C$. abyssinica ( $\mathrm{K} \times \mathrm{A}$ ), only $2 \mathrm{~F}_{1}$ hybrids were obtained with embryo rescue, whereas the reciprocal cross produced no hybrids, even with embryo rescue. The hybrids were confirmed at the morphological, cytological, and molecular levels. In the combinations of A x H and $\mathrm{H} \mathrm{x}$ $\mathrm{A}$, many $\mathrm{BC}_{1}$ hybrids were obtained without embryo rescue. In contrast, in the $\mathrm{K} x \mathrm{~A}$ cross, only $7 \mathrm{BC}_{1}$ plants were obtained with embryo rescue, while no seed set was achieved under self-pollination or in backcrosses without embryo rescue. In the $\mathrm{H}$ x A F $\mathrm{F}_{1}$ hybrids, the pollen stainability was $65.4-86.0 \%$, with an average of $76.9 \%$. In comparison, the pollen viability of hybrids in the reciprocal cross $(\mathrm{Ax} \mathrm{H})$ ranged from 66.2 to
\end{abstract}


$81.1 \%$, with an average of $75.4 \%$. Fertile pollen grains were not found in the $\mathrm{K} \times \mathrm{A} \mathrm{F}_{1}$ hybrids. All $\mathrm{F}_{1}$ hybrids of the 3 crosses $(\mathrm{H} \times \mathrm{A}, \mathrm{A} \times \mathrm{H}$, and $\mathrm{K} \times \mathrm{A}$ ) had the expected $2 \mathrm{n}=75$ chromosomes. AFLP analyses indicated that all $\mathrm{F}_{1}$ hybrids and their progenies had typical bands of the parents. These hybrids and progenies are anticipated to be valuable for future C. abyssinica improvement in breeding programs.

Key words: Crambe abyssinica; Crambe hispanica; Crambe kralikii; Morphology; Interspecific hybrids; Cytogenetics

\section{INTRODUCTION}

Erucic acid is an important fatty acid in the oleochemical industry. The current major industrial source of erucic acid is high-erucic acid rapeseed oil (McNeill, 1997). However, the erucic acid in rapeseed oil has become a major health concern, with many countries around the world directing their attention toward developing rapeseed cultivars that have low erucic acid content (Tallent, 1972). The crucifer Crambe abyssinica $(2 \mathrm{n}=6 \mathrm{x}=90)$ has high erucic acid content (52$59 \%$ ) in its seed oil, in addition to wide climatic and agronomic adaptation; hence, this plant is receiving more focus as an alternative industrial crop (Mikolajczak et al., 1961; Lazzeri et al., 1994; Gardner, 1996; Huang et al., 2013). Massoura et al. (1996) reported that Crambe also has other valuable by-products, such as protein meal and possibly fiber. The acceptance of Crambe meal by the feed industry is based on its attractive price and satisfactory performance as a feed for ruminant animals (Carlson et al., 1996). Crambe is also cultivated in China (Wang et al., 2000).

Since the 1970s, research programs, such as traditional breeding by successive selection within C. abyssinica, have been carried out in many countries to widen this species' genetic variation; however, only limited progress was made because of inadequate genetic variability for important agronomic traits, such as disease resistance, seed yield, and erucic acid content (Mastebroek and Lange, 1997; Warwick and Gugel, 2003). Crambe hispanica $(2 \mathrm{n}=60)$ and Crambe kralikii $(2 \mathrm{n}=60)$ are wild relatives of $C$. abyssinica, and exhibit better tolerance to certain diseases, such as Alternaria, one of the most devastating diseases of C. abyssinica in China. Therefore, these 2 species might provide useful resources of genetic variation for the improvement of C. abyssinica (Mulder and Mastebroek, 1996; White, 1975; White and Solt, 1978).

Interspecific hybridization has been, and continues to be, a useful means for transferring desirable traits from related germplasm into the crop plant of interest, to increase the genetic diversity of cultivated species (Snowdon, 2007; Mohanty et al., 2009). Sexual incompatibility exists between wild and cultivated species, such as the abortion of embryos at an early developmental stage, and the low fertility of $\mathrm{F}_{1}$ hybrids. In many cases, these difficulties may be overcome by embryo rescue and protoplast fusion, which greatly facilitate the production of interspecific hybrids (Zhang et al., 2004; Wen et al., 2008; Prakash et al., 2009). There are numerous examples of successful gene introgressions, with respect to diseases $\mathrm{Hu}$ et al., 2002; Chen et al., 2007), novel fatty acid composition (Wang et al., 2003), and fertility restorer genes for a number of cytoplasmic male sterility systems (Banga et al., 2003). In this study, interspecific crosses of $C$. abyssinica with $C$. hispanica and C. kralikii were undertaken to produce hybrids and progenies for the improvement of C. abyssinica. Morphological, cytogenetic, and molecular characterization of the $\mathrm{F}_{1}$ hybrids was reported. 


\section{MATERIAL AND METHODS}

\section{Plant material and crosses}

Seeds of C. hispanica, C. kralikii, and C. abyssinica were obtained from the USDA (http://plants.usda.gov/core/profile?symbol=CRAB5). The seeds were sown in the field of Hubei University, Wuhan, $30.35^{\circ} \mathrm{N}, 114.17^{\circ} \mathrm{E}$, China. Reciprocal crosses were carried out between $C$. hispanica and C. abyssinica, and C. kralikii and C. abyssinica. Flower buds of the female parent were hand emasculated 1 day before anthesis, and bagged with paper bags. Hand pollination was conducted with freshly collected pollen grains of the male parent one day following emasculation.

About 2-3 weeks after pollination, some swollen siliquas with immature seeds were excised for embryo culture, and the rest were left on the plants for seed harvest. Excised siliquas were rinsed with tap water, surface-sterilized in $70 \%$ ethanol for $3 \mathrm{~min}$, and treated with $0.1 \%$ mercuric chloride for $15 \mathrm{~min}$, followed by 3 rinses in sterile distilled water. The immature embryos were aseptically dissected and transferred to MS agar medium (Murashinge and Skoog, 1962), and kept at $25^{\circ} \mathrm{C}$ in a 12 -h light/12-h dark cycle for about 1 month. Plantlets regenerated from the cultured embryos were multiplied in vitro by subculturing the shoot tips and nodal segments on MS agar medium supplemented with $3.0 \mathrm{mg} / \mathrm{L}$ 6-benzylaminopurine and $0.2 \mathrm{mg} / \mathrm{L}$ $\alpha$-naphthalenacetic acid (NAA). Plantlets formed on this medium were rooted on MS agar medium containing $0.5 \mathrm{mg} / \mathrm{L} \mathrm{NAA}$, and were then transferred to the greenhouse.

\section{Pollen viability and cytological analysis}

The pollen fertility of the hybrids was estimated based on the percentage of stainable pollen grains with $1 \%$ acetocarmine. About 300 pollen grains from 2 flowers of each hybrid were counted under the microscope. Fertile pollen grains were completely rounded, densely stained, and easily distinguishable from small, shrunken, and lightly stained sterile pollen grains.

For chromosome counting at the mitotic metaphase, the immature ovaries of the hybrids were pre-treated with $2 \mathrm{mM} 8$-hydroxyquinoline for $3 \mathrm{~h}$ at room temperature, and fixed in a mixture of $1: 3(\mathrm{v} / \mathrm{v})$ acetic acid/ethanol overnight. Then, the samples were transferred to $70 \%$ alcohol and stored at $-20^{\circ} \mathrm{C}$ until use. The young flower buds used for the meiotic studies were directly fixed in a mixture of 1:3 (v/v) acetic acid/ethanol for at least $24 \mathrm{~h}$, and then stored at $-20^{\circ} \mathrm{C}$. Mitotic and meiotic observations were performed according to the method of $\mathrm{Li}$ et al. (1995).

\section{Amplified fragment length polymorphism (AFLP) analysis}

AFLP analysis was performed on $\mathrm{F}_{1}$ plants/progenies and parents following the procedures of Vos et al. (1995), with some modifications. In brief, $50 \mathrm{ng}$ purified genomic DNA was completely digested by using the restriction endonucleases EcoRI and MseI. Digested DNAs were then ligated to EcoRI and MseI adapters, and the resulting ligation products were amplified by PCR with primers matching the adapters. After 2 PCR steps (pre-selective PCR and selective PCR in turn), the PCR products were loaded onto the gel and resolved. The AFLP profile was obtained with silver staining (Bassam et al., 1991), and bands with 80-1000 bp were scored. 


\section{RESULTS}

\section{Crossability and production of hybrids}

In the cross between $C$. abyssinica and $C$. hispanica, 5 hybrids were obtained with embryo rescue, while $118 \mathrm{~F}_{1}$ hybrids were produced without embryo rescue, when $C$. hispanica was used as the female parent (the combination designated as $\mathrm{H} \mathrm{x} \mathrm{A).} \mathrm{In} \mathrm{their} \mathrm{recipro-}$ cal crosses $(\mathrm{A} \times \mathrm{H}), 232$ hybrids were obtained without embryo rescue (Table 1). From more than 1000 C. kralikii flowers pollinated with the pollen grains of C. abyssinica (K x A), only $2 \mathrm{~F}_{1}$ hybrids were obtained through embryo rescue, whereas reciprocal crosses produced no hybrids, even by embryo rescue (Table 1). $\mathrm{H}$ x A and $\mathrm{A}$ x $\mathrm{H}$ hybrids produced many $\mathrm{BC}_{1}$ progenies after pollination by $C$. abyssinica, whereas $\mathrm{K} \times \mathrm{A}$ hybrids only produced $7 \mathrm{BC}_{1}$ plants, when using embryo culture, after pollination by $C$. abyssinica, while no seed set was achieved under self-pollination or in backcrosses without embryo rescue.

\begin{tabular}{|c|c|c|c|c|c|}
\hline Combinations & $\begin{array}{c}\text { Number of flowers } \\
\text { pollinated }\end{array}$ & $\begin{array}{c}\text { Number of embryos } \\
\text { cultured }\end{array}$ & $\begin{array}{l}\text { Number of } \\
\text { hybrids }^{\mathrm{a}}\end{array}$ & $\begin{array}{l}\text { Number } \\
\text { of hybrids }\end{array}$ & $\begin{array}{c}\text { Index of } \\
\text { crossability }\end{array}$ \\
\hline C. hispanica $\times$ C. abyssinica & 305 & 5 & 5 & 118 & 40.3 \\
\hline C. abyssinica $\times$ C. hispanica & 546 & 0 & 0 & 232 & 42.5 \\
\hline C. kralikii $\times$ C. abyssinica & 1060 & 52 & 2 & 0 & 0.2 \\
\hline C. abyssinica $\times$ C. kralikii & 685 & 5 & 0 & 0 & 0 \\
\hline
\end{tabular}

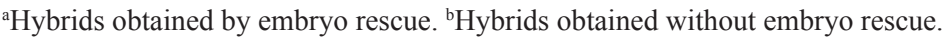

The $\mathrm{H}$ x A hybrids were morphologically intermediate to the parents for many characteristics, including leaf shape, branching structure (Figure 1A-C), and flower size. The $\mathrm{F}_{1}$ hybrids exhibited basal branching as found in C. abyssinica (Figure 1B and C), whereas $C$. hispanica had an obvious primary stem (Figure 1A). The stems and leaves of the $\mathrm{F}_{1}$ hybrids (Figure 1D,) were glabrous, like those of $C$. abyssinica (Figure 1E), whereas the $C$. hispanica leaves were pubescent (Figure $1 \mathrm{~F}$ ). The pollen stainability of the $\mathrm{H} \times \mathrm{A}$ hybrids was 65.4$86.0 \%$, with an average of $76.9 \%$.

The A x H F 1 hybrids showed typical $C$. abyssinica morphology at the seedling stage, but certain differences existed among the individuals at flowering stage (Figure $1 \mathrm{G})$. The purple color and pubescent trait of the male parent $C$. hispanica were expressed to different degrees on the leaf petioles and stems (Figure 1H). The structure of the basic clustering stems of $C$. abyssinica was kept in the $\mathrm{F}_{1}$ hybrids, but there were fewer branches compared to $C$. abyssinica (Figure $1 \mathrm{G}$ and $\mathrm{H}$ ). The petal shape was intermediate between the 2 parents, but the flower size was similar to that of $C$. hispanica and larger than $C$. abyssinica. The pollen viability of the $\mathrm{A} \mathrm{x} \mathrm{H} \mathrm{F}_{1}$ hybrids ranged from 66.2 to $81.1 \%$, with an average of $75.4 \%$.

Many morphological characteristics and inflorescence attributes of the $\mathrm{K}_{\mathrm{A} \mathrm{A} \mathrm{F}}$ hybrids were intermediate between the 2 parents, including leafstalk color (Figure 2A-C), leaf shape (Figure 2D and E), flower buds (Figure 2F), and plant height. The branching pattern was similar to C. kralikii, with an obvious primary stem. The hybrids had flowers with abnormal stamens that were shorter compared to both parents (Figure 2G-I). 

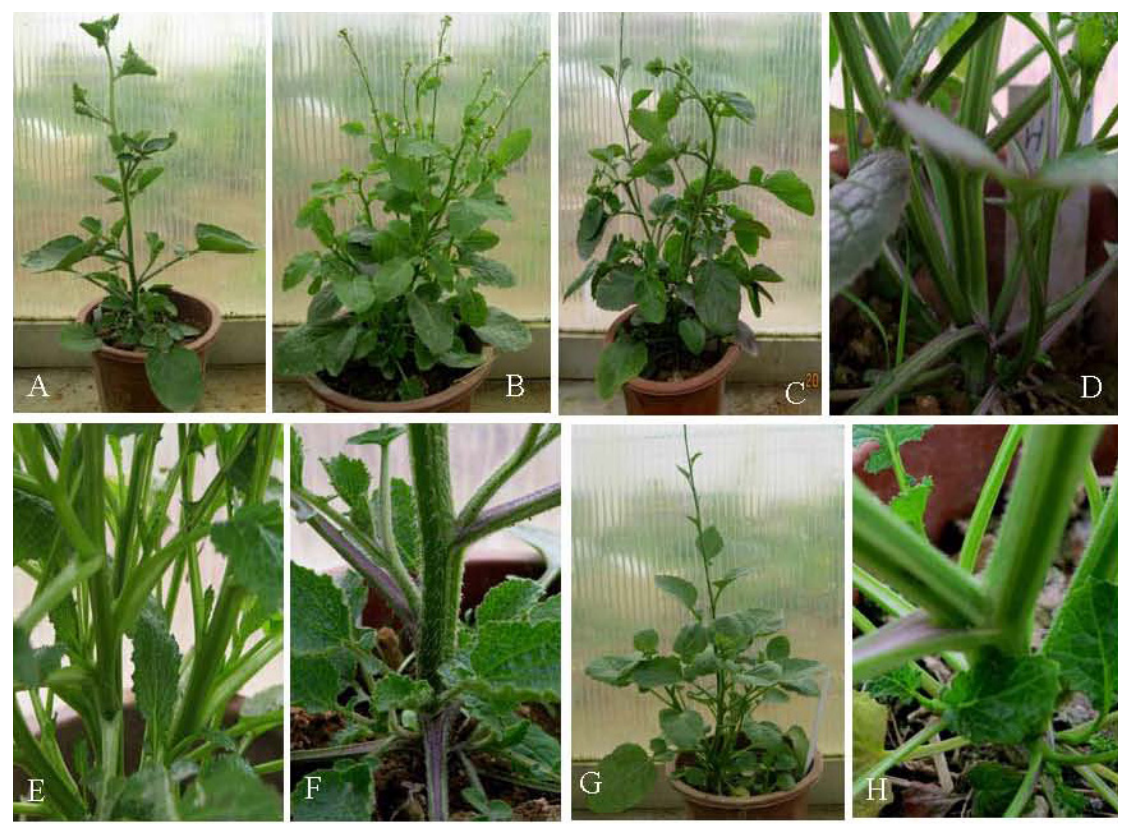

Figure 1. Phenotypes of hybrids from Crambe hispanica $\mathrm{x}$ C. abyssinica and C. abyssinica $\mathrm{x}$ C. hispanica. Flowering plants of $C$. hispanica (A), C. abyssinica (B), hybrids H x A (C). Stems of hybrids H x A (D), $C$. abyssinica $(\mathbf{E})$ and $C$. hispanica $(\mathbf{F})$. G. Flowering plant of hybrid A x H. H. Stem of hybrid A x H.
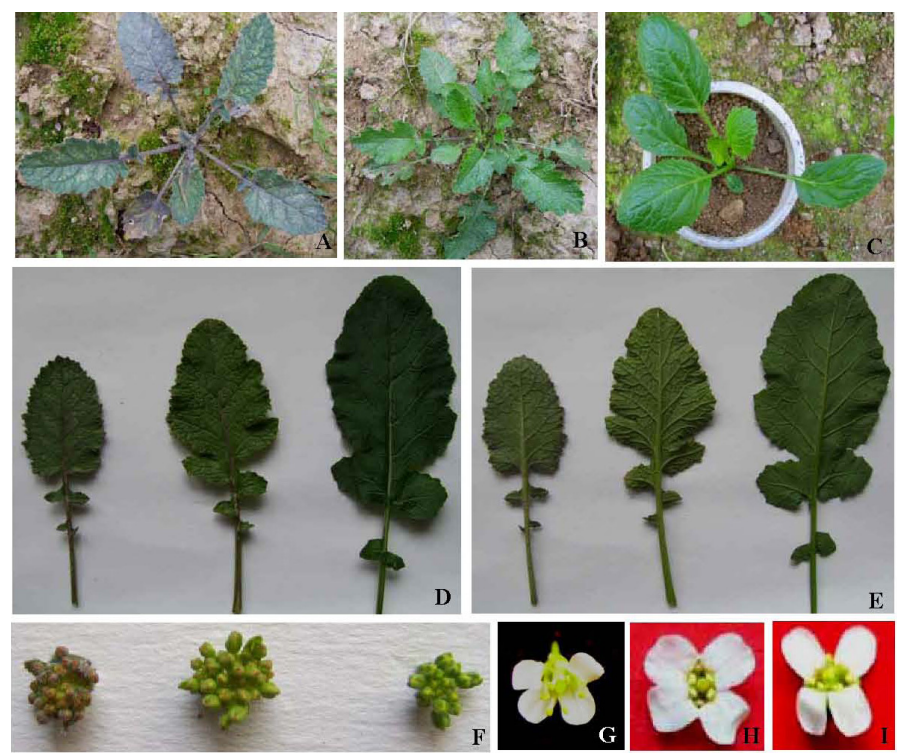

Figure 2. Phenotypes of hybrids from Crambe kralikii x C. abyssinica. Young plants of C. kralikii (A), K x A hybrid (B) and $C$. abyssinica $(\mathbf{C})$. Front surface (D) and back surface (E) of leaves of $C$. kralikii, $\mathrm{K}$ x A hybrid and C. abyssinica (from left to right). F. Flower buds of C. kralikii, K x A hybrid and C. abyssinica. G.-I. Flowers of $C$. kralikii, $\mathrm{K}$ x A hybrid, and C. abyssinica. 


\section{Cytology of the $F_{1}$ hybrids}

All $\mathrm{F}_{1}$ hybrids of the 3 crosses ( $\mathrm{H} \times \mathrm{A}, \mathrm{A} \times \mathrm{H}$ and $\mathrm{K} \times \mathrm{A}$ ) had the expected chromosome number $(2 n=75)$, corresponding to the sum of the haploidy number of the parents. In the pollen mother cells (PMCs) at diakinesis and metaphase I (MI) of the $\mathrm{H} \times \mathrm{A} \mathrm{F}_{1}$ hybrids, a range of chromosome configurations were observed, including 30II + 15I, 25II + 25I, $1 \mathrm{III}+31 \mathrm{II}+$ 10I (Figure 3A), and 2III + 30II + 9I (Figure 3B). The ranges of univalents and bivalents were 3-33 and 17-36, respectively, while the average chromosome association was $1.95 \mathrm{III}+28.40$ II +11.75 I (Table 2). In the PMCs at anaphase I (AI), many types of chromosome segregation ratios were recorded, with different chromosome numbers in each polar group. The 38:37 segregation ratio was most frequent in $33.3 \%$ of PMCs. The $\mathrm{A} \times \mathrm{H} \mathrm{F}_{1}$ hybrids also showed various chromosome pairing configurations in the PMCs at diakinesis and MI. The most frequent pairing, 31II+13I (Figure 3C), occurred in about 30.4\% of the PMCs. The ranges of univalents and bivalents were 3-38 and 14-36, respectively. The average chromosome association was $2.38 \mathrm{III}+$ 27.95II + 14.67I (Table 2). The majority of AI PMCs showed segregation ratios of 45:30, 41:34, 40:35, and 38:37 (Figure 3D). The $\mathrm{K} \mathrm{x} \mathrm{A} \mathrm{F}_{1}$ hybrids had variable pairings, with a high frequency of univalent. A maximum of 63 univalents (Figure 4A) was observed in about 9.7\% PMCs, and a maximum of 3 trivalents was observed in 3.7\% PMCs. The ranges of univalents and bivalents were $28-63$ and 6-22, respectively. The average pairing association was $1.08 \mathrm{III}+12.16 \mathrm{II}$ $+48.16 \mathrm{I}$ (Table 2). Various segregation ratios appeared, with 45:30 (Figure 4B) being the most frequent in about $31.1 \%$ PMCs. Numerous chromosomal abnormalities were observed at AI and AII, including the late disjunction of bivalents (Figure 4C), chromosome bridges (Figure 4D), laggards, and micronuclei. These abnormalities caused male sterility in $\mathrm{F}_{1}$ hybrids.

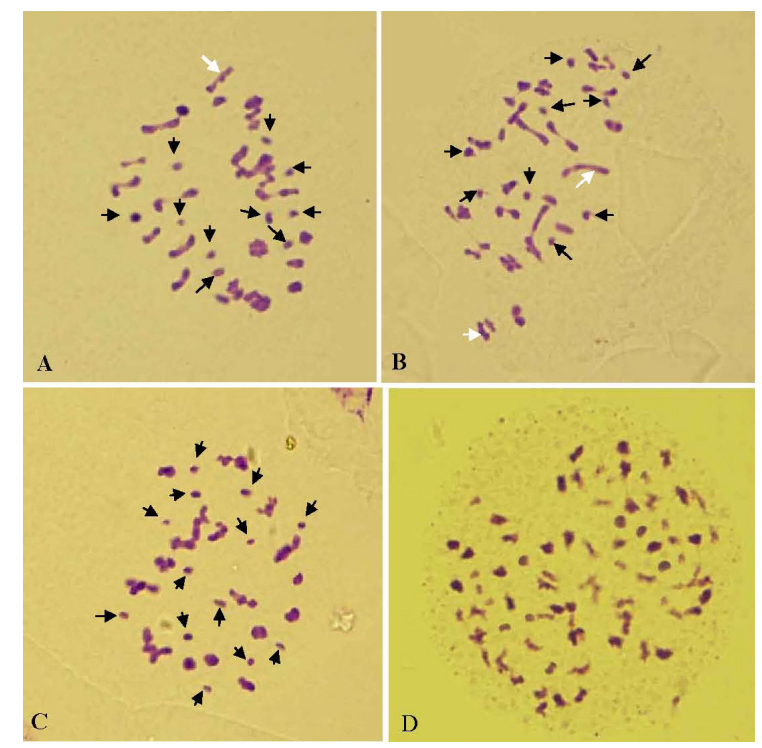

Figure 3. Meiosis of hybrids between Crambe abyssinica and C. hispanica (A x H, H x A). A. One MI PMC of $\mathrm{H}$ $\mathrm{x}$ A hybrid with 1III (white arrow) $+31 \mathrm{II}+10 \mathrm{I}$ (black arrows). B. One MI PMC of $\mathrm{H}$ x A hybrid with $2 \mathrm{III}$ (white arrows) $+30 \mathrm{II}+9 \mathrm{I}$ (black arrows). C. One diakinesis PMC of A x H hybrid with 31II + 13I (black arrows). D. One AI PMC of A x H hybrid with 38:37 segregation. 
Table 2. Meiotic configurations in the interspecific hybrids among Crambe abyssinica, C. hispanica and C. kralikii.

\begin{tabular}{|c|c|c|c|c|c|}
\hline \multirow[t]{2}{*}{ Combinations } & \multirow[t]{2}{*}{$2 n$} & \multirow{2}{*}{$\frac{\text { PMCs }}{\text { Observed }}$} & \multicolumn{3}{|c|}{ Chromosome pairing per PMCs/ranges } \\
\hline & & & Univalents & Bivalents & Trivalents \\
\hline $\mathrm{H} \times \mathrm{A}$ & 75 & 34 & $\begin{array}{r}11.75 \\
3-33\end{array}$ & 28.40 & $\begin{array}{l}1.95 \\
0-7\end{array}$ \\
\hline $\mathrm{AxH}$ & 75 & 31 & $\begin{array}{r}14.67 \\
3-38\end{array}$ & $\begin{array}{l}27.95 \\
14-36\end{array}$ & $\begin{array}{l}2.38 \\
0-4\end{array}$ \\
\hline $\mathrm{K} \times \mathrm{A}$ & 75 & 37 & $\begin{array}{l}48.16 \\
28-63\end{array}$ & $\begin{array}{r}12.16 \\
6-22\end{array}$ & $\begin{array}{l}1.08 \\
0-3\end{array}$ \\
\hline
\end{tabular}

$\mathrm{PMC}=$ pollen mother cells.
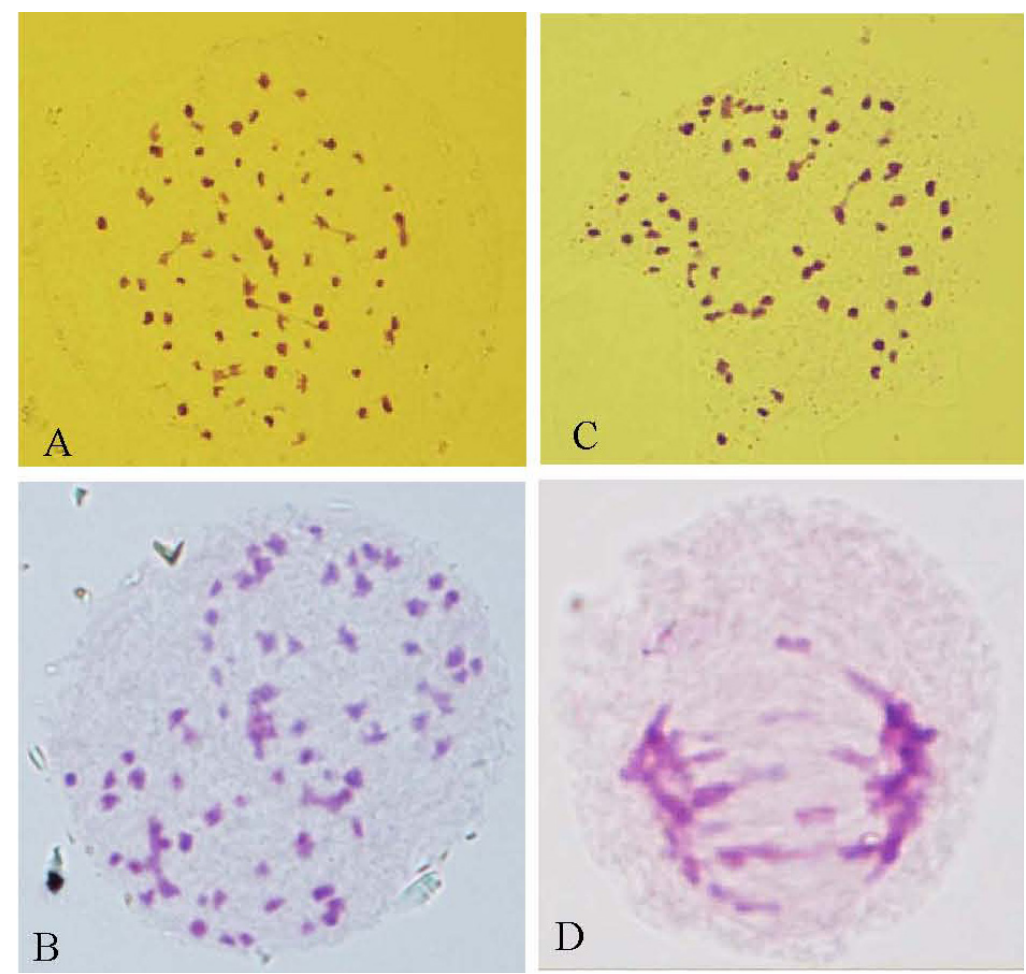

Figure 4. Cytology of the hybrids between Crambe kralikii and C. abyssinica. A. One diakinesis PMC with 6II + 63I. B. One AI PMC with 45 (above): 30 (below) segregation. C. One anaphase I PMC showing late disjunction of bivalents. D. One AI PMC with lagging chromosomes and chromosome bridges.

\section{AFLP analysis}

AFLP analysis was carried out on $\mathrm{K} \times \mathrm{A}, \mathrm{A} \times \mathrm{H}$, and $\mathrm{H} \times \mathrm{A}$ hybrids by using 10 randomly selected primer pairs that yielded clear polymorphic band patterns specific to the parents (Figures 5 and 6). All $\mathrm{F}_{1}$ hybrids and their progenies expressed typical bands of the parents, confirming the hybrid identities. The absence of bands in one or both parents, and novel bands for both parents, were found in all cross-combinations. 


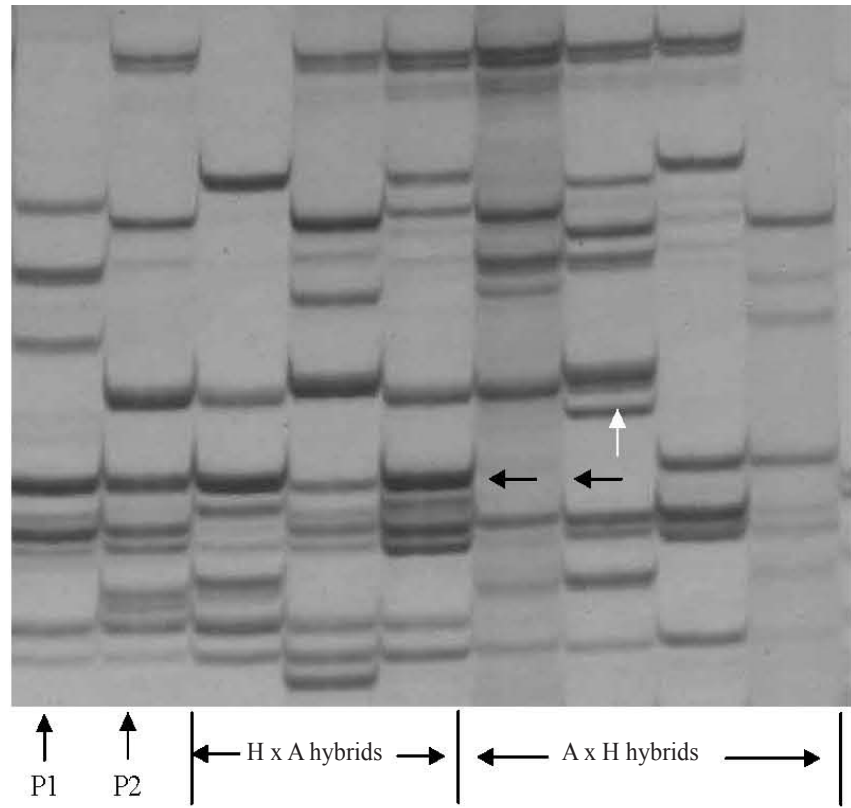

Figure 5. RepresentativeAFLP profiles generated from one primer pair combination 5'-GACTGCGTACCAATTCAC T-3' and 5'-GATGAGTCCTGAGTAACGA-3' in hybrids between Crambe abyssinica and $C$. hispanica. P1 $=C$. abyssinica. $\mathrm{P} 2=C$. hispanica. Black arrows showing deleted bands and white arrow showing novel band.

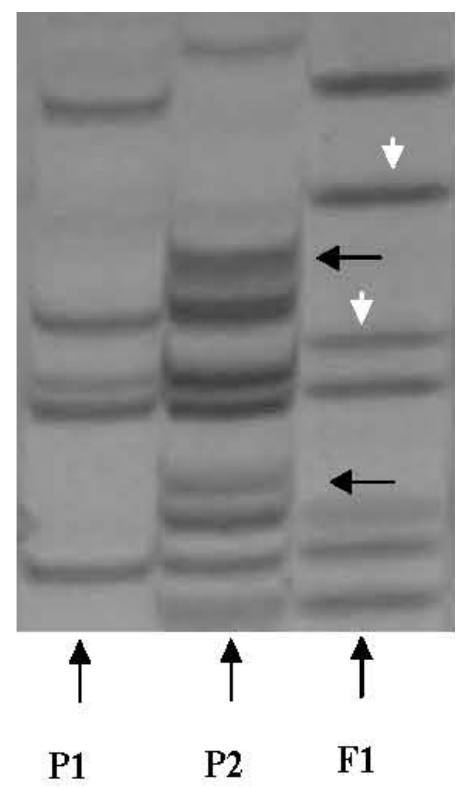

Figure 6. Representative AFLP profiles generated from one primer combination 5'-GACTGCGTACCAATTCAGC3'and 5'-GATGAGTCCTGAGTAACCG-3' in the hybrid between Crambe kralikii and C. abyssinica. P1 $=C$. abyssinica. $\mathrm{P} 2=C$. kralikii. Black arrows showing deleted bands and white arrows showing novel bands. 


\section{DISCUSSION}

The employment of large-scale germplasm collections of the important world food crops has significantly contributed to the success of plant breeding programs. To successfully breed new potential industrial crops, their gene pools must also be widened. Several cultivars of C. abyssinica have been released, such as 'Prophet', 'Indy', 'Meyer' (Lessman, 1975), 'BelAnn', and 'BelEnzian' (Campbell et al., 1986) through mass selection. However, further improvement is restricted because of a lack of variation within C. abyssinica for important agricultural characteristics. In the present study, interspecific hybrids and their backcross plants were obtained using combinations of $\mathrm{A} \times \mathrm{H}, \mathrm{H} \times \mathrm{A}$, and $\mathrm{K} \times \mathrm{A}$. The identity of the $\mathrm{F}_{1}$ hybrids was confirmed at the morphological, cytological, and molecular levels. All of the $\mathrm{F}_{1}$ hybrids exhibited phenotypic features that were intermediate to both parents. AFLP analysis indicated that all the $\mathrm{F}_{1}$ hybrids and their progenies had typical bands of the parents, confirming the hybrid identities. The absence of bands in one or both parents and novel bands for two parents were found in all cross-combinations. This means that chromosome recombination and DNA elimination occurred in the genomes of the hybrids.

Interspecific hybrids are also used for phylogenetic and evolutionary studies. Genomic analysis was originally based on observations of chromosome pairings in hybrids between diploid analyzers and their polyploid relatives. If the chromosomes were paired in multiples of the basic number of the genus, it was assumed that common genomes were present (Lilienfield and Kihara, 1951). Some difficulties arose when the number of chromosome pairs was not close to the exact multiples of the basic number. In these cases, it was assumed that some genomic differentiation had taken place. In addition, it is invalid, in most cases, to infer genomic relationships from chromosome pairing in diploid hybrids. This is because residual homoeology might lead to synapsis, which might be interpreted as homology (Zhao and Kimber, 1984). Even though this method was subjective, it worked well, and provided an essentially correct picture of evolution for Brassicas, wheat, and other species (Kihara, 1919; Sax, 1918, 1922; Morinaga 1933, 1934; Nagaharu, 1935; Lilienfield and Kihara, 1951; Morris and Sears, 1967; Zhao and Kimber, 1984; Espinasse et al., 1995).

There are about 30 species in the genus Crambe, with the taxonomic and genetic relationships between some species remaining controversial (Mulder and Mastebroek, 1996; Warwick and Gugel, 2003). Based on morphological (Jonsell, 1976) and molecular data (Warwick and Gugel, 2003), C. abyssinica and C. hispanica were reported to have conspecific status and were classified into one species, but may be distinguished by chromosome numbers. Data assimilated by Francisco-Ortega et al. (2002) indicated that $C$. abysinica is very closely clustered with $C$ hispanica, followed by $C$. filiformis, and then $C$. kralikii. The crosses between $C$. abyssinica and $C$. hispanica have been carried out; however, cytogenetic data are not available (Meier and Lessman, 1972). In this study, $\mathrm{F}_{1}$ hybrids and backcrossing progenies between $C$. abyssinica and C. hispanica were easily obtained and showed a high frequency of meiotic pairing in PMCs at diakinesis, which resulted in a high degree of fertility (Table 2 and Figure 2). In the hybrids $\mathrm{H} \times \mathrm{A} / \mathrm{A} \times \mathrm{H}$, up to 60 chromosomes are averagely involved in the formation of bivalents and trivalents, suggesting that nearly all 30 chromosomes from $C$. hispanica are homologous enough to the 30 chromosomes of 45 from $C$. abyssinica to be paired and then that $C$. hispanica might be an ancestor of $C$. abyssinica. Since $C$. abyssinica is possibly one hexaploid with $x=15, C$. hispanica seems to be one tetraploid containing two genomes with $x$ 
$=15$, which share high degree of homology with the two genomes in C. abyssinica. The extra pairing of more than 30 bivalents in these pentaploid hybrids also suggests that homoeology might exist within the partaking genome of $C$. abyssinica. The lower crossability of $C$. kralikii $\mathrm{x} C$. abyssinica combination showed their more distant relationship, which was supported by the lower frequency of chromosome pairing, widespread chromosomal abnormalities and the sterility for male and female gametes in the hybrids.

In conclusion, interspecific $\mathrm{F}_{1}$ hybrids and their backcross generations were obtained from the crosses of $C$. abyssinica with $C$. hispanica and C. kralikii. The progenies with beneficial traits are anticipated to provide a new and valuable resource for the genetic improvement of $C$. abyssinica. Selection for earliness increased seed yield, and higher seed oil content is in progress.

\section{ACKNOWLEDGMENTS}

Research supported by the EC FP7 Project ICON (\#211400), the Swedish Research Links Project, the NSFC (\#30771382, \#30671334, \#30971807, \#31201238), the Wuhan Science and Technology Bureau (\#201231234464), and MOST.

\section{REFERENCES}

Banga SS, Deol JS and Banga SK (2003). Alloplasmic male-sterile Brassica juncea with Enarthrocarpus lyratus cytoplasm and the introgression of gene(s) for fertility restoration from cytoplasm donor species. Theor. Appl. Genet. 106: 1390-1395.

Bassam BJ, Caetano-Anolles G and Gresshoff PM (1991). Fast and sensitive silver staining of DNA in polyacrylamide gels. Anal. Biochem. 196: 80-83.

Campbell TA, Crock J, Williams JH, Hang AN, et al. (1986). Registration of 'BelAnn' and 'BelEnzian' Crambe. Crop Sci. 26: 1082-1083.

Carlson KD, Gardner JC, Anderson VL and Hanzel JJ (1996). Crambe: New Crop Success. In: Progress in New Crops (Janick J, ed.). ASHS Press, Alexandria, 306-322.

Chen HF, Wang H and Li ZY (2007). Production and genetic analysis of partial hybrids in intertribal crosses between Brassica species (B. rapa, B. napus) and Capsella bursa-pastoris. Plant Cell Rep. 26: 1791-1800.

Espinasse A, Foueillassarl J and Kimber G (1995). Cytogenetical analysis of hybrids between sunflower and four wild relatives. Euphytica 82: 65-72.

Francisco-Ortega J, Fuertes-Aguilar J, Kim SC, Santos-Guerra A, et al. (2002). Phylogeny of the Macaronesian endemic Crambe section Dendrocrambe (Brassicaceae) based on internal transcribed spacer sequences of nuclear ribosomal DNA. Am. J. Bot. 89: 1984-1990.

Gardner JC (1996). Crambe: new routes from farm to market. INFORM 7: 986-988.

Hu Q, Ahdersen SB, Dixelius C and Hansen LN (2002). Production of fertile intergeneric somatic hybrids between Brassica napus and Sinapis arvensis for the enrichment of the rapeseed gene pool. Plant Cell Rep. 21: 147-152.

Huang B, Yang Y, Luo T, Wu S, et al. (2013). Correlation, regression and path analyses of seed yield components in Crambe abyssinica, a promising industrial oil crop. Am. J. Plant Sci. 4: 42-47.

Jonsell B (1976). Some tropical African Cruciferae. Bot. Notiser 129: 123-130.

Kihara H (1919). Ueber cytologische studien bei einigen getreidearten. 1. Spezies-bastarde des weizens und weizenroggenbastard. Bot. Mag. 32: 17-38.

Lazzeri L, Leoni O, Conte LS and Palmieri S (1994). Some technological characteristics and potential uses of Crambe abyssinica products. Ind. Crops Prod. 3: 103-112.

Lessman KJ (1975). Variation in Crambe, Crambe abyssinica Hochst. J. Am. Oil. Chem. Soc. 52: 386-389.

Li Z, Liu HL and Luo P (1995). Production and cytogenetics of intergeneric hybrids between Brassica napus and Orychophragmus violaceus. Theor. Appl. Genet. 1: 131-136.

Lilienfield FA and Kihara H (1951). Genome analysis in Triticum and Aegilops. Concluding review. Cytologia 16: 101121. 
Massoura E, Vereijken JM, Kolster P and Derksen JTP (1996). Isolation and Functional Properties of Proteins from Crambe abyssinica Oil Seeds. In: Progress in New Crops (Janick J, ed.). ASHS Press, Alexandria, 322-327.

Mastebroek HD and Lange W (1997). Progress in a crambe cross breeding programme. Ind. Crop. Prod. 6: 221-227.

McNeill GP (1997). Enzymatic Process for the Isolation of Erucic Acid from Vegetable Oils. U.S. Patent No. $(5,633,151)$.

Meier VD and Lessman KJ (1972). Heritabilities of some agronomic characters for the interspecific cross of Crambe abyssinica and C. hispanica. Crop Sci. 13: 237-240.

Mikolajczak KL, Miwa TK, Earle FR and Wolff IA (1961). Search for new industrial oils. V. Oils of Cruciferae. J. Am. Oil Chem. Soc. 38: 678-681.

Mohanty A, Chrungu B, Verma N and Shivanna KR (2009). Broadening the genetic base of crop Brassicas by production of new intergeneric hybrid. Czech J. Genet. Plant Breed 45: 117-122.

Morinaga T (1933). Interspecific hybridisation in Brassica: 5. The cytology of F1 hybrid of B. carinata and B. alboglabra. Jpn. J. Bot. 6: 467-475.

Morinaga T (1934). Interspecific hybridisation in Brassica: 6. The cytology of B. juncea and B. nigra. Cytologia 6: 62-67.

Morris R and Sears ER (1967). The Cytogenetics of Wheat and its Relatives. In: Wheat and Wheat Improvement (Quisenberry KS and Reitz LP, eds.). American Society of Agronomy, Madison, 19-87.

Mulder JH and Mastebroek HD (1996). Variation for agronomic characteristics in Crambe hispanica, a wild relative of Crambe abyssinica. Euphytica 89: 267-278.

Murashinge T and Skoog F (1962). A revised medium for rapid growth and bioassay with tobacco tissue cultures. Physiol. Plant 15: 473-479.

Nagaharu U (1935). Genomic analysis of Brassica with special reference to the experimental formation of B. napus and peculiar mode of fertilization. Jpn. J. Bot. 7: 389-452.

Prakash S, Bhat SR, Quiros CF, Kirti PB, et al. (2009). Brassica and its close allies: cytogenetics and evolution. Plant Breed Rev. 31: 21-187.

Sax K (1918). The behavior of the chromosomes in fertilization. Genetics 3: 309-327.

Sax K (1922). Sterility in wheat hybrids. II. Chromosome behavior in partially sterile hybrids. Genetics 7: 513-552.

Snowdon RJ (2007). Cytogenetics and genome analysis in Brassica crops. Chromosome Res. 15: 85-95.

Tallent WH (1972). Improving high-erucic acid oilseeds: chemically or genetically? JAOCS 49: 15-19.

Vos P, Hogers R, Bleeker M, Reijans M, et al. (1995). AFLP: a new technique for DNA fingerprinting. Nucleic Acids Res. 23: 4407-4414

Wang YP, Tang JS, Chu CQ and Tian J (2000). A preliminary study on the introduction and cultivation of Crambe abyssinica in China, an oil plant for industrial uses. Ind. Crops Prod. 12: 47-52.

Wang YP, Sonntag K and Rudloff E (2003). Development of rapeseed with high erucic acid content by asymmetric somatic hybridization between Brassica napus and Crambe abyssinica. Theor. Appl. Genet. 106: 1147-1155.

Warwick SI and Gugel RK (2003). Genetic variation in the Crambe abyssinica-C. hispanica-C. glabrata complex. Genet. Resour. Crop Evol. 50: 291-305.

Wen J, Tu JX, Li ZY, Fu TD, et al. (2008). Improving ovary and embryo culture techniques for efficient resynthesis of Brassica napus from reciprocal crosses between yellow-seeded diploids B. rapa and B. oleracea. Euphytica 162: 81-89.

White GA (1975). Distinguishing characteristics of Crambe abyssinica and C. hispanica. Crop Sci. 15: 91-93.

White GA and Solt M (1978). Chromosome numbers in Crambe, Crambella and Hemicrambe. Crop Sci. 18: 160-161.

Zhang GQ, Tang GX, Song WJ and Zhou WJ (2004). Resynthesizing Brassica napus from interspecific hybridization between Brassica rapa and B. oleracea through ovary culture. Euphytica 140: 181-187.

Zhao YH and Kimber G (1984). New hybrids with D genome wheat relatives. Genetics 106: 509-515. 